๔ Open Access Full Text Article

\title{
Immunogenetic Relationship of HLA-G I4 bp Insertion/Deletion Polymorphism and Toll-Like Receptor 9 with Systemic Lupus Erythematosus in Egyptian Patients: A Case-Control Study
}

\author{
Shrouk A Mohammed (D'), Laila M Al Kady', Ghada S Boghdadi (i)', Ghada A Dawa², \\ Marian A Gerges (D)', Maher A El Shafai' \\ 'Medical Microbiology and Immunology Department, Faculty of Medicine, Zagazig University, Zagazig, Egypt; ${ }^{2}$ Rheumatology and Rehabilitation \\ Department, Faculty of Medicine, Zagazig University, Zagazig, Egypt \\ Correspondence: Marian A Gerges, Medical Microbiology and Immunology Department, Faculty of Medicine, Zagazig University, Zagazig, 445I 9 , \\ Egypt, Tel +201003819530, Email MAGerges@zu.edu.eg
}

\begin{abstract}
Introduction: The level of expression of the immunoregulatory human leukocyte antigen-G (HLA-G) has been suggested to play a role in the immunopathogenesis of systemic lupus erythematosus (SLE). A 14 bp insertion/deletion (ins/del) polymorphism in the 3 'untranslated region of $H L A-G$ gene may influence the level of expression. The role of Toll-like receptor 9 (TLR9) in the pathogenesis of SLE has been highlighted. Data among Egyptian patients are quite limited.

Purpose: To detect the association of HLA-G $14 \mathrm{bp}$ ins/del gene polymorphism with the susceptibility to SLE and to correlate TLR9 serum level with disease activity among Egyptian patients.

Patients and Methods: A case-control study that included 102 SLE female patients and 102 healthy matched volunteers as controls was carried out. Disease activity in patients was determined using the modified Systemic Lupus Erythematosus Disease Activity Index (SLEDAI). HLA-G $14 \mathrm{bp}$ ins/del genotype was detected by polymerase chain reaction (PCR). TLR9 serum level was estimated using enzyme-linked immunosorbent assay (ELISA) technique.

Results: The ins/ins genotype was significantly increased among SLE patients compared to healthy subjects $(58.8 \%$ vs $9.8 \%$; odds ratio $[\mathrm{OR}]=11.79, \mathrm{P}<0.001)$. The $14 \mathrm{bp}$ ins allele was significantly more frequent in SLE patients than in healthy subjects $(65.7 \%$ vs $27.9 \%$, respectively) and significantly associated with an increased risk of SLE (OR 4.94, P $<0.001$ ). The mean TLR9 serum level showed a significant increase in SLE patients compared to healthy subjects (397.04 \pm 137.86 vs $195.22 \pm 45.14 \mathrm{ng} / \mathrm{L}, \mathrm{p}<0.001)$ and was significantly associated with disease activity as well as to patients' $H L A-G$ genotypes $(\mathrm{p}<0.001)$.

Conclusion: Among Egyptian population, $H L A-G 14$ bp ins/ins homozygous genotype and ins allele may constitute a potential risk for SLE susceptibility, while TLR9 serum level is significantly associated with disease activity.
\end{abstract}

Keywords: human leukocyte antigen-G, Toll-like receptor 9, gene polymorphism, systemic lupus erythematosus

\section{Introduction}

Systemic lupus erythematosus (SLE) is a prototype of multi-system autoimmune diseases, triggered by a combination of several genetic and environmental factors. ${ }^{1,2}$ More than 90 genetic loci have been studied and found to be associated with SLE development and progress in different populations. ${ }^{3}$ Among Egyptian patients, different genetic polymorphisms have been studied and found to be associated with SLE as polymorphisms in the gene coding for the autoimmune regulator (AIRE), type I interferon (IFN) pathway, interleukin 27, programmed cell death 1 (PD1), tumor necrosis factor (TNF- $\alpha$ ) and IFN- $\gamma .{ }^{4-8}$ However, the role of the human leukocyte antigen-G (HLA-G) gene has not been addressed before among Egyptian patients. 
HLA-G is a non-classical HLA class Ib molecule located on chromosome 6p21.31. Unlike the classical HLA class I, HLA-G has a limited polymorphism in its coding region. It encompasses seven isoforms, including four membranebound (mHLA-G; HLA-G1, -G2, -G3, and -G4) and three soluble (sHLA-G; HLA-G5, -G6, and -G7) isoforms, which may be generated by alternative splicing of $H L A-G$ primary transcripts. ${ }^{9}$ Under physiologic conditions, HLA-G is principally detected at the maternal-fetal interface in extra-villous cytotrophoblast cells as it creates a state of tolerance to protect the fetus from the maternal immune response against the fetal semi-allograft. ${ }^{10}$ The immune-tolerogenic influence of HLA-G molecules is exerted primarily through the interaction of membrane-bound and soluble HLA-G to their specific inhibitory receptors (immunoglobulin-like transcript; ILT2, ILT4) expressed on immune cells as natural killer cells, $\mathrm{CD}^{+}$and $\mathrm{CD}^{+}$lymphocytes and dendritic cells, which in turn results in downregulation of inflammatory processes and immune tolerance. ${ }^{11}$ In addition to the fetal tissues, restricted tissue distribution of HLA-G has been documented in adult immune-privileged organs including the cornea, thymus, pancreatic islets, endothelial cell precursors and erythroblasts. ${ }^{12}$ It can also be induced under pathologic conditions such as viral infection, tumors, transplantation, inflammatory and autoimmune disorders. ${ }^{13}$

A possible association between HLA-G expression levels and susceptibility to develop SLE, or modulate its clinical features, has been shown in different populations with distinct ethnic background. ${ }^{14-16}$

A $14 \mathrm{bp}$ insertion/deletion (ins/del) polymorphism in exon 8, the 3'untranslated region (3'UTR) of the HLA-G mature RNA, has been suggested to influence the expression level of HLA-G molecules as the insertion of the $14 \mathrm{bp}$ fragment in the 3 'UTR is thought to affect the stability of HLA-G mRNA. ${ }^{17}$ Indeed, the HLA-G 14 bp ins/ins genotype has been associated with lower surface expression and decreased soluble HLA-G production. ${ }^{18-20}$ This eventually results in activation of inflammatory cells which could contribute to the development of inflammatory diseases, malignancies, pathological pregnancy, and several autoimmune diseases like SLE. ${ }^{1,13,21}$

On the other hand, Toll-like receptor 9 (TLR9) represents a stimulatory component of the immune system which may be connected functionally to HLA-G. ${ }^{22}$ TLR9 is a class of pattern recognition receptors (PRR) recognizing DNA with unmethylated $\mathrm{CpG}$ motifs and is almost expressed in B cells and plasmacytoid dendritic cells. It has been demonstrated to play a crucial role in the pathogenesis of SLE. ${ }^{23}$ The deficiency in clearance of cellular debris and the accumulation of endogenous nucleic acids in patients with SLE may thus be recognized by TLR9 triggering the production of type I IFN and other proinflammatory cytokines. ${ }^{24}$

Though it remains controversial, ${ }^{25,26}$ this has been hypothesized to play a critical step for lupus initiation and development as B cell TLR9 is required for the abnormal survival, proliferation, and differentiation of autoantibodies secreting B and plasma cells. ${ }^{27,28}$

The expression level of TLR9 has been shown to correlate with the expression of CD85j or ILT2, a receptor for HLA$\mathrm{G}$, and to positively correlate with HLA-G expression suggesting a physiologic connection between suppressive factors of the immune system (HLA-G) and elements of innate immunity (TLR9). ${ }^{22}$

To better elucidate these issues among Egyptian patients, this study was designed to detect the association of $H L A-G$ $14 \mathrm{bp}$ ins/del polymorphism with the susceptibility to SLE and further correlate TLR9 serum level with disease activity among Egyptian patients.

\section{Patients and Methods}

A case-control study was carried out between December 2019 and February 2021 in the Immunology Research Lab at Medical Microbiology and Immunology Department, and the Rheumatology and Rehabilitation Department, Faculty of Medicine, Zagazig University. The study included 102 SLE female patients with their age ranging from 18 to 55 years old, in addition to 102 age-matched apparently healthy female volunteers, as controls, with age ranging from 20 to 53 years old. All enrolled patients fulfilled the diagnostic criteria for SLE defined by the Systemic Lupus International Collaborating Clinics (SLICC) criteria of 2012. ${ }^{29}$ Patients with autoimmune diseases other than SLE, extreme age group, and drug-induced lupus were excluded from the study. Personal history was recorded for all patients including age, and smoking history. Clinical data such as onset and duration of disease, malar rash, falling of hair, photosensitivity, oral ulcer, discoid lesion, arthritis, neurological manifestations, lupus nephritis (LN), and secondary antiphospholipid syndrome (APLS) were collected from patients' records. Disease activity was determined for each patient using the 
modified Systemic Lupus Erythematosus Disease Activity Index (SLEDAI). ${ }^{30}$ Routine laboratory and autoimmune parameters such as complete blood count (CBC) profile, complement (C) 3 and $\mathrm{C} 4$ level, antinuclear antibodies (ANA), ANA pattern, anti-double stranded DNA (dsDNA) antibodies, and anticardiolipin antibodies (ACLA) were all investigated for each patient.

\section{Ethical Approval}

The Institutional Review Board (IRB) and the ethical committee of Zagazig University Hospitals approved this study, approval number (IRB\#\#5617-16-10-2019). All subjects gave written informed consent before enrollment. This work was conducted in accordance with the World Medical Association Declaration of Helsinki.

\section{Blood Sampling}

Five $\mathrm{mL}$ of whole venous blood were withdrawn from each participant under complete aseptic conditions and divided into two parts; two $\mathrm{mL}$ were collected in EDTA tube for DNA extraction and HLA-G genotyping and three $\mathrm{mL}$ were collected in plain vacutainer, incubated for $30 \mathrm{~min}$ at $37 \mathrm{C}^{\circ}$ then centrifuged for serum separation and TLR9 estimation.

\section{Genotyping and Detection of HLA-G 14 bp Polymorphism at exon 8 (3' UTR)}

Genotyping of HLA-G was performed for all participants. Whole blood DNA was extracted from EDTA-treated blood samples by using PREP-RAPID GENETICS DNA extraction kit (DNA technology, Russia) according to the manufacturer's instructions. Polymorphism at HLA-G was detected using polymerase chain reaction (PCR) that utilizes two specific primers to amplify the targeted fragment of the chosen gene. The following primers were used; forward primer (5'-GTGATGGGCTGTTTAAAGTGTCACC-3'), and reverse primer (5'-GGAAGGAATGCAGTTCAGCATGA-3'). ${ }^{31}$ Reactions were done in a total volume of $25 \mu \mathrm{L}$ containing $4 \mu \mathrm{L}(\sim 100 \mathrm{ng})$ of genomic DNA with an ultimate concentration of other reagents (iNtRON Biotechnology, Korea): 1x reaction buffer, $2.5 \mathrm{mM}$ of each dNTP, $1.5 \mathrm{mM}$ $\mathrm{MgCl}_{2}, 2.5 \mathrm{U}$ Taq polymerase, $1 \mu \mathrm{L}$ of each primer $(10 \mathrm{pmol} / \mu \mathrm{L})$. Cycling conditions were as follows; initial denaturation at $95^{\circ} \mathrm{C}$ for $180 \mathrm{~s}$ followed by 35 cycles of denaturation at $95^{\circ} \mathrm{C}$ for $60 \mathrm{~s}$, annealing at $64^{\circ} \mathrm{C}$ for $60 \mathrm{~s}$, elongation at $72^{\circ} \mathrm{C}$ for $10 \mathrm{~min}$, and final elongation at $72^{\circ} \mathrm{C}$ for $10 \mathrm{~min}$. Amplified products were visualized under UV light in a $2 \%$ agarose gel with ethidium bromide $\left(0.5 \mu \mathrm{g} / \mathrm{mL}\right.$ ) (Sigma, USA). A $100 \mathrm{bp}$ DNA ladder (KAPA ${ }^{\mathrm{TM}}$, USA) was used to detect the size of the resulting fragment/fragments.

\section{Interpretation}

Depending upon the insertion or deletion of $14 \mathrm{bp}$ sequence in $H L A-G$ exon 8, PCR products of length 224 or $210 \mathrm{bp}$ were generated, respectively. ${ }^{31}$ Three different genotypes were detected; homozygous for $14 \mathrm{bp}$ insertion [ins/ins] $(+/+14$ bp) producing one fragment measuring $224 \mathrm{bp}$, homozygous for $14 \mathrm{bp}$ deletion [del/del] $(-/-14 \mathrm{bp})$ producing one fragment measuring $210 \mathrm{bp}$ and heterozygous for $14 \mathrm{bp}$ insertion/deletion [ins/del] $(+/-14 \mathrm{bp})$ where two fragments $(224$ bp and $210 \mathrm{bp}$ ) were detected.

\section{Estimation of TLR9 Serum Levels}

Serum level of TLR9 was estimated by a sandwich ELISA technique using the human TLR-9 ELISA Bioassay Technology (BT Lab, China) ELISA kit (catalog no.: E0356Hu) according to the instructions of the manufacturer. The mean absorbance was estimated for each sample at $450 \mathrm{~nm}$ wavelength. The level of TLR9 was calculated using calibration curves with a sensitivity of $2.53 \mathrm{ng} / \mathrm{L}$.

\section{Statistical Analysis}

The sample size was calculated to be 204 (102 case and 102 control) using open-Epi at CI 95\% and power of study 80\%. SPSS program (Statistical Package for Social Science) version 27.0 was used for data processing. Qualitative data were represented as frequencies and relative percentages. Chi-square $\left(\chi^{2}\right)$ test was used to calculate difference between qualitative variables. Quantitative data were expressed as mean \pm standard deviation (SD). Independent " $\mathrm{t}$ " test, ANOVA (F-test), Tukey post hoc test and Kruskal Wallis test were used to calculate the difference between quantitative 
variables. Spearman correlation coefficient was used to assess the strength of the relationship between two sets of data. $P$ values less than 0.05 indicate significant results.

\section{Results}

This study included 102 SLE female patients with their ages ranging between 18-55 year (mean $31.61 \pm 11.17$ year) and disease duration from 2 to 13 year (mean $5.94 \pm 2.57$ years). Enrolled healthy female subjects $(n=102)$ had a mean age of $32.65 \pm 4.56$ years with no significant difference $(\mathrm{P}>0.05)$ between both groups. The mean SLEDAI of SLE patients in the present study was $10.31 \pm 6.08$ where $11.8 \%$ of SLE patients had very high activity. Hair falling represented the commonest phenotype in patients (60.8\%). About half of the studied patients had LN (52.9\%), malar rash (50\%), and arthritis (49\%). Other clinical and laboratory parameters of SLE patients are presented in Table 1.

\section{HLA-G I4 Bp Polymorphism}

The results revealed that the frequencies of $H L A-G 14$ bp genotypes and alleles in both SLE patients and healthy subjects were significantly different $(\mathrm{P}<0.001)$. The ins/ins genotype was more frequent in SLE group $(58.8 \%)$ compared to controls (9.8\%). The $14 \mathrm{bp}$ ins allele was significantly more frequent in SLE group than in controls (65.7\% vs $27.9 \%$, respectively, $\mathrm{P}<0.001)$. The higher frequency of $14 \mathrm{bp}$ ins allele in SLE group was found to be associated with an increased risk of SLE (OR 4.94, $\mathrm{P}<0.001$ ) (Table 2 and Figure 1).

When the $H L A-G$ genotypes were related to various demographic and clinical features of SLE patients (Table 3), no significant association $(\mathrm{P}>0.05)$ between $H L A-G$ genotypes and disease onset or disease duration was evident. However, regarding clinical manifestations, a significant association was found between ins/ins genotype and both LN $(\mathrm{P}=0.02)$ and hair falling $(\mathrm{P}=0.002)$. Meanwhile, arthritis was significantly associated with $\mathrm{del} / \mathrm{del}$ genotype $(\mathrm{P}<$ $0.001)$. On the other hand, no significant association $(P>0.05)$ between genotypes and laboratory findings was found. The results further revealed a non-significant association between SLE patients' genotypes and the positivity to anti-ds DNA antibodies $(\mathrm{P}=0.07)$. However, when patients with positive anti-ds DNA were further divided into two groups based on the presence (anti-dsDNA+/LN+, $\mathrm{n}=58$ ) or absence (anti-dsDNA+/LN-, $\mathrm{n}=25$ ) of LN, a significant association was found between the ins/ins genotype and the anti-dsDNA $+\mathrm{LN}+$ group $(\mathrm{P}=0.02)$. Additionally, the results revealed significantly higher SLEDAI $(\mathrm{P}=0.03)$ among patients with ins/ins genotype (mean $11.3 \pm 6.25)$ compared to other genotypes (mean $8.36 \pm 6.67,10 \pm 2.08$ for del/del and ins/del, respectively), where all patients with very high disease activity and $73.3 \%$ of those with high activity exhibited the ins/ins genotype $(\mathrm{P}<0.001)$ Table 3.

\section{Analysis of TLR9 Serum Levels}

Analysis of TLR9 serum level in the studied groups demonstrated that SLE patients recorded significantly higher mean serum levels than in the control group $(397.04 \pm 137.86 \mathrm{ng} / \mathrm{L}$ vs $195.22 \pm 45.14 \mathrm{ng} / \mathrm{L}, \mathrm{p}<0.001)$ Figure 2.

When the relation of TLR9 serum level to various clinical and laboratory features of SLE patients was investigated, the results revealed that TLR9 serum level was significantly associated with hair falling $(\mathrm{P}=0.002)$, photosensitivity $(\mathrm{P}=$ $0.02)$, arthritis $(\mathrm{P}=0.04)$, and $\mathrm{LN}(\mathrm{P}<0.001)$. However, no significant association was found between the serum level of TLR9 and other clinical manifestations (Table 4). Interestingly, TLR9 serum level was significantly higher in antidsDNA antibody-positive group $(\mathrm{n}=83)$ compared with anti-dsDNA antibody-negative group $(\mathrm{n}=19)(427.95 \pm 132.14$ vs $262.11 \pm 58.68, \mathrm{P}<0.001)$. In contrast, no significant association was found between serum level of TLR9 and the presence of ACLA or any other CBC abnormalities (Table 4).

Moreover, to investigate the correlation of TLR9 with disease activity, we analyzed the correlation of TLR9 serum level with SLEDAI scores in SLE patients using Spearman correlation coefficient test. The expression of TLR9 serum level was found to be positively correlated with SLEDAI scores $(r \mathrm{~s}=0.496, \mathrm{P}<0.001)$.

The TLR9 level was then compared between both groups of anti-dsDNA positive patients (anti-dsDNA+/LN+ and anti-dsDNA+/LN-) to further investigate the relationship between TLR9 level with organ damage, particularly LN. A significant increase in TLR9 expression in the anti-dsDNA+/LN+ group as opposed to the anti-dsDNA+/LN- group was observed (Mean $417.08 \pm 135.24$ vs $362.6 \pm 85.75 \mathrm{ng} / \mathrm{L}, \mathrm{P}=0.03$ ) (Table 4). 
Table I Demographic Characteristics, Clinical Manifestations, Lab Findings and Disease Activity of SLE Patients

\begin{tabular}{|c|c|c|c|}
\hline \multicolumn{2}{|l|}{ Variable } & \multicolumn{2}{|l|}{$(n=102)$} \\
\hline Age (Years) & $\begin{array}{l}\text { Mean } \pm \text { SD } \\
\text { Median (Range) }\end{array}$ & \multicolumn{2}{|l|}{$\begin{array}{l}31.61 \pm 11.17 \\
29(18-55)\end{array}$} \\
\hline Disease duration (Years) & $\begin{array}{l}\text { Mean } \pm \text { SD } \\
\text { Median (Range) }\end{array}$ & \multicolumn{2}{|l|}{$\begin{array}{l}5.94 \pm 2.57 \\
5.5(2-13)\end{array}$} \\
\hline \multicolumn{2}{|l|}{ Variable } & No & (\%) \\
\hline Onset & $\begin{array}{l}\text { Early ( } \leq 20 \text { years) } \\
\text { Late ( }>20 \text { years) }\end{array}$ & $\begin{array}{l}39 \\
63\end{array}$ & $\begin{array}{l}38.2 \\
61.8\end{array}$ \\
\hline Manifestations & $\begin{array}{l}\text { Malar rash } \\
\text { Hair falling } \\
\text { Photosensitivity } \\
\text { Oral ulcers } \\
\text { Discoid lesion } \\
\text { Arthritis } \\
\text { Neurological manifestations (headache) } \\
\text { Lupus nephritis } \\
\text { Secondary APLS }\end{array}$ & $\begin{array}{l}51 \\
62 \\
55 \\
24 \\
17 \\
50 \\
12 \\
54 \\
11\end{array}$ & $\begin{array}{l}50 \\
60.8 \\
53.9 \\
23.5 \\
16.7 \\
49 \\
11.8 \\
52.9 \\
10.8\end{array}$ \\
\hline \multirow[t]{2}{*}{ Laboratory findings } & $\begin{array}{l}\text { CBC profile abnormalities } \\
\text { Leukopenia } \\
\text { Anemia } \\
\text { Thrombocytopenia }\end{array}$ & $\begin{array}{l}70 \\
12 \\
53 \\
5\end{array}$ & $\begin{array}{l}68.7 \\
11.8 \\
52 \\
4.9\end{array}$ \\
\hline & $\begin{array}{l}\text { Low C3 level } \\
\text { Low C4 level } \\
\text { Positive ANA } \\
\text { ANA pattern: } \\
\text { Homogeneous } \\
\text { Speckled } \\
\text { Nuclear } \\
\text { Peri-nuclear } \\
\text { Positive anti-dsDNA } \\
\text { Positive ACLA }\end{array}$ & $\begin{array}{l}54 \\
54 \\
102 \\
52 \\
36 \\
7 \\
7 \\
83 \\
31\end{array}$ & $\begin{array}{l}52.9 \\
52.9 \\
100 \\
51 \\
35.2 \\
6.9 \\
6.9 \\
81.4 \\
30.4\end{array}$ \\
\hline \multirow[t]{2}{*}{ SLEDAI } & $\begin{array}{l}\text { Mild activity } I-5 \\
\text { Moderate activity 6-10 } \\
\text { High activity II-19 } \\
\text { Very high activity } \geq 20\end{array}$ & $\begin{array}{l}29 \\
31 \\
30 \\
12\end{array}$ & $\begin{array}{l}28.4 \\
30.4 \\
29.4 \\
11.8\end{array}$ \\
\hline & $\begin{array}{l}\text { Mean } \pm S D \\
\text { Range }\end{array}$ & \multicolumn{2}{|l|}{$\begin{array}{l}10.31 \pm 6.08 \\
10(2-22)\end{array}$} \\
\hline
\end{tabular}

Notes: Normal WBCs count $=4-11 \times 10^{3} / \mathrm{mm}^{3}$ and leukopenia $<4000 / \mathrm{mm}^{3}$, Normal hemoglobin level=12-16 g/dl and anemia $<12 \mathrm{~g} / \mathrm{dl}$, Normal platelet count $=150-400 \times 10^{3} / \mathrm{mm}^{3}$ and thrombocytopenia $<100,000 / \mathrm{mm}^{3}$, Normal C3 level $=90-210 \mathrm{mg} / \mathrm{dl}$, Normal C4 level $=13-$ $75 \mathrm{mg} / \mathrm{dl}$.

Abbreviations: SD, standard deviation; APLS, antiphospholipid syndrome; CBC, complete blood count; C3, complement 3 level; C4, complement 4 level; ANA, antinuclear antibodies; Anti-ds DNA, Anti-double stranded DNA antibodies; ACLA, anticardiolipin antibodies; SLEDAI, systemic lupus erythematosus disease activity index.

Furthermore, the $H L A-G$ genotypes of the studied participants were related to TLR9 serum level to find if there is any possible association. The results revealed that those having ins/ins genotype recorded the highest TLR9 levels in both SLE patients and healthy subjects demonstrating a significant association $(\mathrm{P}<0.001)$. Interestingly, SLE patients having 
Table 2 Genotypes and Allele Frequency of HLA-G Among the Studied Groups

\begin{tabular}{|c|c|c|c|c|c|}
\hline $\begin{array}{l}\text { Group } \\
\text { Genotypes }\end{array}$ & SLE Patients $(n=102)$ No (\%) & Controls $(n=102)$ No (\%) & $\chi^{2}$ & $P$ value & OR \\
\hline Del/del & $28(27.5 \%)$ & $55(53.9 \%)$ & Ref & - & 1 \\
\hline Ins/del & $14(13.7 \%)$ & $37(36.3 \%)$ & 0.58 & 0.45 & $0.74(0.4-1.6)$ \\
\hline Ins/ins & $60(58.8 \%)$ & $10(9.8 \%)$ & 41.99 & $<0.001 * *$ & II.79 (5.25-26.48) \\
\hline \multicolumn{6}{|l|}{ Allele } \\
\hline Del & $70(34.3 \%)$ & $147(72.1)$ & \multirow[t]{2}{*}{58.4} & \multirow[t]{2}{*}{$<0.001 * *$} & \multirow[t]{2}{*}{$4.94(3.24-7.52)$} \\
\hline Ins & $134(65.7 \%)$ & 57 (27.9\%) & & & \\
\hline
\end{tabular}

Note: **Highly significant.

Abbreviations: $\chi^{2}$, Chi square test; OR, odds ratio; Del, deletion; Ins, insertion.

ins/ins genotype recorded higher TLR9 levels than healthy subjects with the same genotype (mean $450.14 \pm 143.69$ vs $223.33 \pm 28.43 \mathrm{ng} / \mathrm{L}$ ) Figure 3.

\section{Discussion}

The heterogeneity of SLE among different ethnicities strongly supports the influence of different genetic backgrounds on the critical biological mechanisms underlying the disease. Understanding the influence of different genetic backgrounds on the pathogenesis of the disease may improve disease risk prediction. Additionally, it may help develop new targeted therapeutic strategies. ${ }^{32}$

In this study, hair falling, LN, malar rash and arthritis represented the main phenotypes of SLE patients. This comes consistent with previous studies carried out among Egyptian patients where musculoskeletal (arthritis), mucocutaneous (rash), and LN were the most common phenotypes. ${ }^{4,6}$

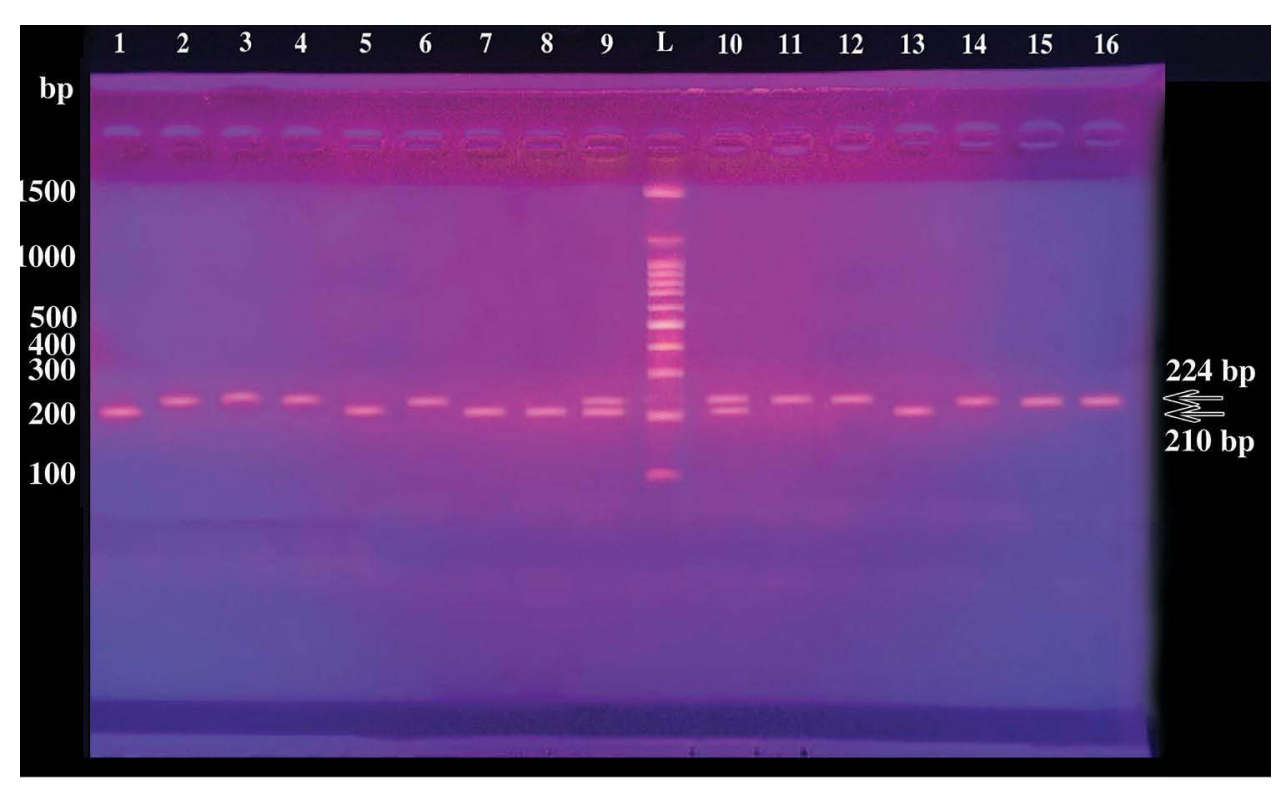

Figure I Gel electrophoresis of PCR products demonstrating different HLA-G genotypes of the studied participants. Lane L: I00-bp DNA Ladder; lanes 2, 3, 4, 6, I I, I2, I4, 15, 16: HLA-G homozygotes ins/ins (+|4bp/+|4bp); lanes 9, I0: HLA-G heterozygotes ins/del (+|4bp/-I4bp); lanes I, 5, 7, 8, I3: HLA-G homozygotes del/del (-I4bp/-I4bp). Depending upon the insertion or deletion of $14 \mathrm{bp}$ sequence in HLA-G exon 8, PCR products of length 224 or $210 \mathrm{bp}$ were generated, respectively. Three different genotypes homozygous for $14 \mathrm{bp}$ insertion [ins/ins] (+/+14 bp) 224 bp, homozygous for 14 bp deletion [del/del] ( $-1-14$ bp) 210 bp and heterozygous for I4 bp insertion/ deletion [ins/del] (+/-I4 bp) 224 bp and 210 bp were generated. 
Table 3 Relation Between Genotype Frequency of HLA-G and Clinical Manifestations, Laboratory Findings and Disease Activity Among SLE Patients

\begin{tabular}{|c|c|c|c|c|c|c|c|c|c|c|}
\hline \multicolumn{2}{|l|}{ Variable } & \multirow{2}{*}{\multicolumn{2}{|c|}{$\begin{array}{l}\begin{array}{l}\text { Del/Del } \\
(n=28)\end{array} \\
32.5 \pm 8.9 \\
31.5(20-47)\end{array}$}} & \multirow{2}{*}{\multicolumn{2}{|c|}{$\begin{array}{l}\text { Del/Ins } \\
(n=14)\end{array}$}} & \multirow{2}{*}{\multicolumn{2}{|c|}{ 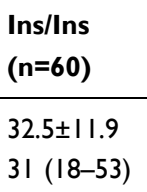 }} & \multirow{2}{*}{\begin{tabular}{|l|} 
Test \\
$2.4^{\wedge}$ \\
\end{tabular}} & \multirow{2}{*}{$\begin{array}{l}\mathbf{P} \\
0.2\end{array}$} & \multirow{2}{*}{$\begin{array}{l}\text { Post Hoc } \\
-\end{array}$} \\
\hline Age (Years) & $\begin{array}{l}\text { Mean } \pm \text { SD } \\
\text { Median (Range) }\end{array}$ & & & & & & & & & \\
\hline Duration (Years) & $\begin{array}{l}\text { Mean } \pm \text { SD } \\
\text { Median (Range) }\end{array}$ & \multicolumn{2}{|c|}{$\begin{array}{l}5.8 \pm 2.4 \\
5(3-10)\end{array}$} & \multicolumn{2}{|c|}{$\begin{array}{l}5 \pm 1.04 \\
5(4-6)\end{array}$} & \multicolumn{2}{|c|}{$\begin{array}{l}6.2 \pm 2.9 \\
6(2-13)\end{array}$} & $2.8^{\#}$ & 0.3 & - \\
\hline Variable & & No & (\%) & No & (\%) & No & (\%) & $\chi^{2}$ & $\mathbf{P}$ & Within Groups \\
\hline Onset & $\begin{array}{l}\text { Early ( } \leq 20 \text { years) } \\
\text { Late ( }>20 \text { years) }\end{array}$ & $\begin{array}{l}22 \\
6\end{array}$ & $\begin{array}{l}34.9 \\
15.4\end{array}$ & $\begin{array}{l}7 \\
7\end{array}$ & $\begin{array}{l}11.1 \\
17.9\end{array}$ & $\begin{array}{l}34 \\
26\end{array}$ & $\begin{array}{l}54 \\
66.7\end{array}$ & 4.8 & 0.09 & - \\
\hline Manifestations & $\begin{array}{l}\text { Malar rash } \\
\text { Hair falling } \\
\text { Photosensitivity } \\
\text { Oral ulcers } \\
\text { Discoid lesion } \\
\text { Arthritis } \\
\text { Neurological manifestations } \\
\text { Lupus nephritis } \\
\text { Secondary APLS }\end{array}$ & $\begin{array}{l}15 \\
4 \\
3 \\
23\end{array}$ & $\begin{array}{l}27.3 \\
16.7 \\
17.6 \\
46\end{array}$ & $\begin{array}{l}11 \\
5 \\
4 \\
6\end{array}$ & $\begin{array}{l}20 \\
20.8 \\
23.5 \\
12\end{array}$ & $\begin{array}{l}29 \\
15 \\
10 \\
21\end{array}$ & $\begin{array}{l}52.7 \\
62.5 \\
58.8 \\
42\end{array}$ & $\begin{array}{l}1.47 \\
7.51 \\
\\
0.23\end{array}$ & $\begin{array}{l}0.9 \\
0.002 * \\
0.12 \\
0.28 \\
0.34 \\
<0.001 * * \\
0.48 \\
0.02 * \\
0.9\end{array}$ & $\begin{array}{l}- \\
<0.001 * * 1 \\
0.13^{2} \\
0.004^{* * 3} \\
- \\
- \\
- \\
0.03^{* 1} \\
<0.00 I^{*} *^{2} \\
0.58^{3} \\
- \\
0.26^{1} \\
0.006^{* 2} \\
0.36^{3} \\
-\end{array}$ \\
\hline Laboratory findings & $\begin{array}{l}\text { CBC profile abnormalities } \\
\text { Leukopenia } \\
\text { Anemia } \\
\text { Thrombocytopenia } \\
\text { C3 level } \\
\text { Low } \\
\text { Normal } \\
\text { C4 level } \\
\text { Low } \\
\text { Normal } \\
\text { ANA Pattern } \\
\text { Homogeneous } \\
\text { Speckled } \\
\text { Nuclear } \\
\text { Peri-nuclear } \\
\text { Anti-dsDNA } \\
\text { Positive } \\
\text { Negative } \\
\text { ACLA } \\
\text { Positive } \\
\text { Negative } \\
\text { Anti-dsDNA/LN } \\
\text { Anti-dsDNA+/LN+ }(n=58) \\
\text { Anti-dsDNA+/LN- }(n=25)\end{array}$ & $\begin{array}{l}19 \\
5 \\
12 \\
2 \\
15 \\
13 \\
15 \\
13 \\
11 \\
12 \\
2 \\
3\end{array}$ & $\begin{array}{l}27.1 \\
33.9 \\
22.6 \\
40 \\
27.8 \\
22.9 \\
27.8 \\
22.9 \\
21.2 \\
33.3 \\
28.5 \\
42.9 \\
22.9 \\
47.4 \\
35.5 \\
23.9 \\
25.9 \\
16\end{array}$ & $\begin{array}{l}8 \\
6 \\
8 \\
6\end{array}$ & $\begin{array}{l}14.8 \\
12.5 \\
14.8 \\
12.5 \\
\\
5.8 \\
22.2 \\
28.5 \\
14.2\end{array}$ & $\begin{array}{l}45 \\
7 \\
36 \\
2 \\
31 \\
29 \\
31 \\
29 \\
38 \\
16 \\
3 \\
3 \\
53 \\
7\end{array}$ & $\begin{array}{l}64.3 \\
58.3 \\
67.9 \\
40 \\
\\
57.4 \\
60.4 \\
57.4 \\
60.4 \\
73 \\
44.5 \\
42.9 \\
42.9 \\
63.9 \\
36.8 \\
48.4 \\
63.4 \\
55.1 \\
84\end{array}$ & $\begin{array}{l}5.5 \\
2.9 \\
3.96 \\
0.8 \\
\\
0.14\end{array}$ & $\begin{array}{l}0.06 \\
0.2 \\
0.1 \\
0.7 \\
\\
0.93\end{array}$ & $\begin{array}{l}- \\
0.28^{1} \\
0.24^{2} \\
0.022^{3}\end{array}$ \\
\hline
\end{tabular}

(Continued) 
Table 3 (Continued).

\begin{tabular}{|c|c|c|c|c|c|c|c|c|c|c|}
\hline \multicolumn{2}{|l|}{ Variable } & \multicolumn{2}{|c|}{$\begin{array}{l}\text { Del/Del } \\
(n=28)\end{array}$} & \multicolumn{2}{|c|}{$\begin{array}{l}\text { Del/Ins } \\
(n=\mid 4)\end{array}$} & \multicolumn{2}{|c|}{$\begin{array}{l}\text { Ins/Ins } \\
(n=60)\end{array}$} & \multirow{3}{*}{$\begin{array}{l}\text { Test } \\
33.34\end{array}$} & \multirow{3}{*}{$\begin{array}{l}\mathbf{P} \\
<0.001^{* *}\end{array}$} & \multirow{4}{*}{$\begin{array}{l}\text { Post Hoc } \\
0.002^{* 1} \\
<0.001^{* * 2} \\
0.30^{3}\end{array}$} \\
\hline \multirow[t]{6}{*}{ SLEDAI } & Mild activity $\mathrm{I}-5$ & 18 & 62.1 & 2 & 6.9 & 9 & 31 & & & \\
\hline & Moderate activity 6-10 & 8 & 25.8 & 6 & 19.4 & 17 & 54.8 & & & \\
\hline & High activity $11-19$ & 2 & 6.7 & 6 & 20 & 22 & 73.3 & & & \\
\hline & Very high activity $\geq 20$ & 0 & 0 & 0 & 0 & 12 & 100 & & & \\
\hline & Mean \pm SD & \multirow{2}{*}{\multicolumn{2}{|c|}{$\begin{array}{l}8.36 \pm 6.67 \\
4(2-17)\end{array}$}} & \multirow{2}{*}{\multicolumn{2}{|c|}{$\begin{array}{l}10 \pm 2.08 \\
10(8-12)\end{array}$}} & \multirow{2}{*}{\multicolumn{2}{|c|}{$\begin{array}{l}11.3 \pm 6.25 \\
10(3-22)\end{array}$}} & $4.21^{\#}$ & $0.03 *$ & $0.04 * 1$ \\
\hline & Range & & & & & & & & & $0.03 *^{2}$ \\
\hline
\end{tabular}

Notes: Normal WBCs count $=4-11 \times 10^{3} / \mathrm{mm}^{3}$ and leukopenia $<4000 / \mathrm{mm}^{3}$, Normal hemoglobin level $=12-16 \mathrm{~g} / \mathrm{dl}$ and anemia $<12 \mathrm{~g} / \mathrm{dl}$, Normal platelet count $=150-400$ $\times 10^{3} / \mathrm{mm}^{3}$ and thrombocytopenia $<100,000 / \mathrm{mm}^{3}$, Normal C3 level $=90-210 \mathrm{mg} / \mathrm{dl}$, Normal C4 level =13- $75 \mathrm{mg} / \mathrm{dl}$. $\chi^{2}$. Chi square test; ${ }^{\wedge}$, ANOVA test; ${ }^{\#} \mathrm{Kruskal}$ Wallis test; Post-hoc of ANOVA, Groups with different letters are statistically significant $(\mathrm{P}<0.05)$; PI, Del/del versus Del/ins; P2, Ins/ins versus Del/del; P3, Del/ins versus Ins/ins; *Significant; **Highly significant.

Abbreviations: SD, standard deviation; Del, deletion; Ins, insertion; APLS, antiphospholipid syndrome; CBC, complete blood count; C3, complement 3 level; C4, complement 4 level; ANA, antinuclear antibodies; Anti-ds DNA, Anti-double stranded DNA antibodies; ACLA, anticardiolipin antibodies; SLEDAI, systemic lupus erythematosus disease activity index;

The present study demonstrated a significant association between $H L A-G$ 3'UTR polymorphisms ( $H L A-G$ ins/del rs371194629), previously suggested to have functional significance, ${ }^{17}$ with SLE susceptibility for the first time among Egyptian patients. A significant over-presentation of the HLA-G ins allele has been observed in SLE patients versus healthy subjects with a significant difference in the frequency of ins/ins genotype among both groups $(\mathrm{P}<0.001, \mathrm{OR}=$ 11.79) highlighting it as a potential risk factor for SLE development among those patients.

The frequency of $H L A-G 14 \mathrm{bp}$ ins allele and its association to other pathologic conditions have been addressed among Egyptian patients with inconsistent results where it was found to be raised significantly $(\mathrm{P}=0.0004)$ in females with recurrent spontaneous abortion (67\%) compared to females with normal pregnancy (41\%) constituting a greater risk for recurrent spontaneous abortion $(\mathrm{P}=0.0003, \mathrm{OR}=2.9$ ). In another study, the ins allele was the most frequently detected among multiple sclerosis Egyptian patients and controls (62.5\% and $70 \%$, respectively) and no significant difference between both groups has been recorded $(\mathrm{P}=0.305)$. On the other hand, the del allele constituted a higher risk for non-Hodgkin lymphoma among Egyptian patients compared to healthy subjects $(\mathrm{P}<0.001){ }^{33-35}$

In different ethnic groups, conflicting results have been reported on the involvement of HLA-G in SLE. However, different published reports including meta-analysis studies confirmed the association of the $14 \mathrm{bp}$ insertion allele as a risk factor for SLE. ${ }^{14,36-38}$ In contrast, studies conducted on different ethnic groups did not find this association. ${ }^{39,40}$

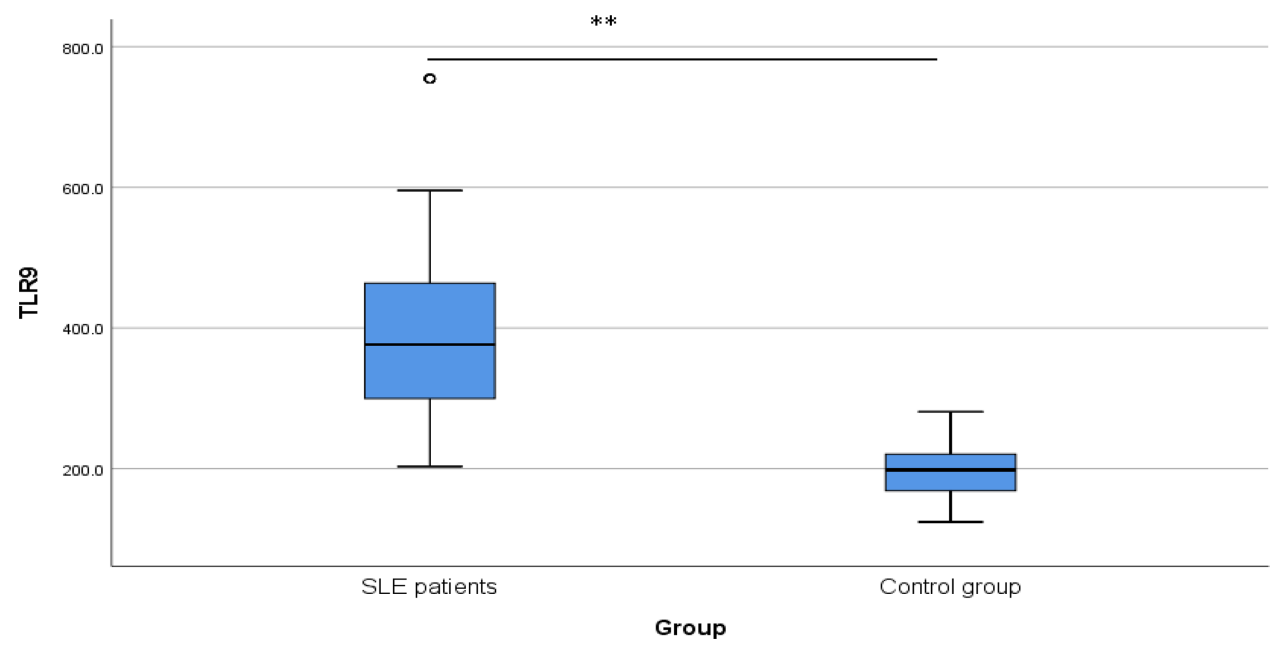

Figure 2 TLR9 serum level ( $\mathrm{ng} / \mathrm{L})$ among the studied groups. A box plot diagram demonstrating a significant difference ${ }^{* *}(P<0.00 \mathrm{I})$ between the mean serum level of TLR9 in SLE patients $(n=102$, mean $397.04 \mathrm{ng} / \mathrm{L})$ and that of controls $(\mathrm{n}=102$, mean $195.22 \mathrm{ng} / \mathrm{L})$. 
Table 4 Relation Between TLR9 Level (ng/L) and Clinical Features, Laboratory Findings and Disease Activity in SLE Patients

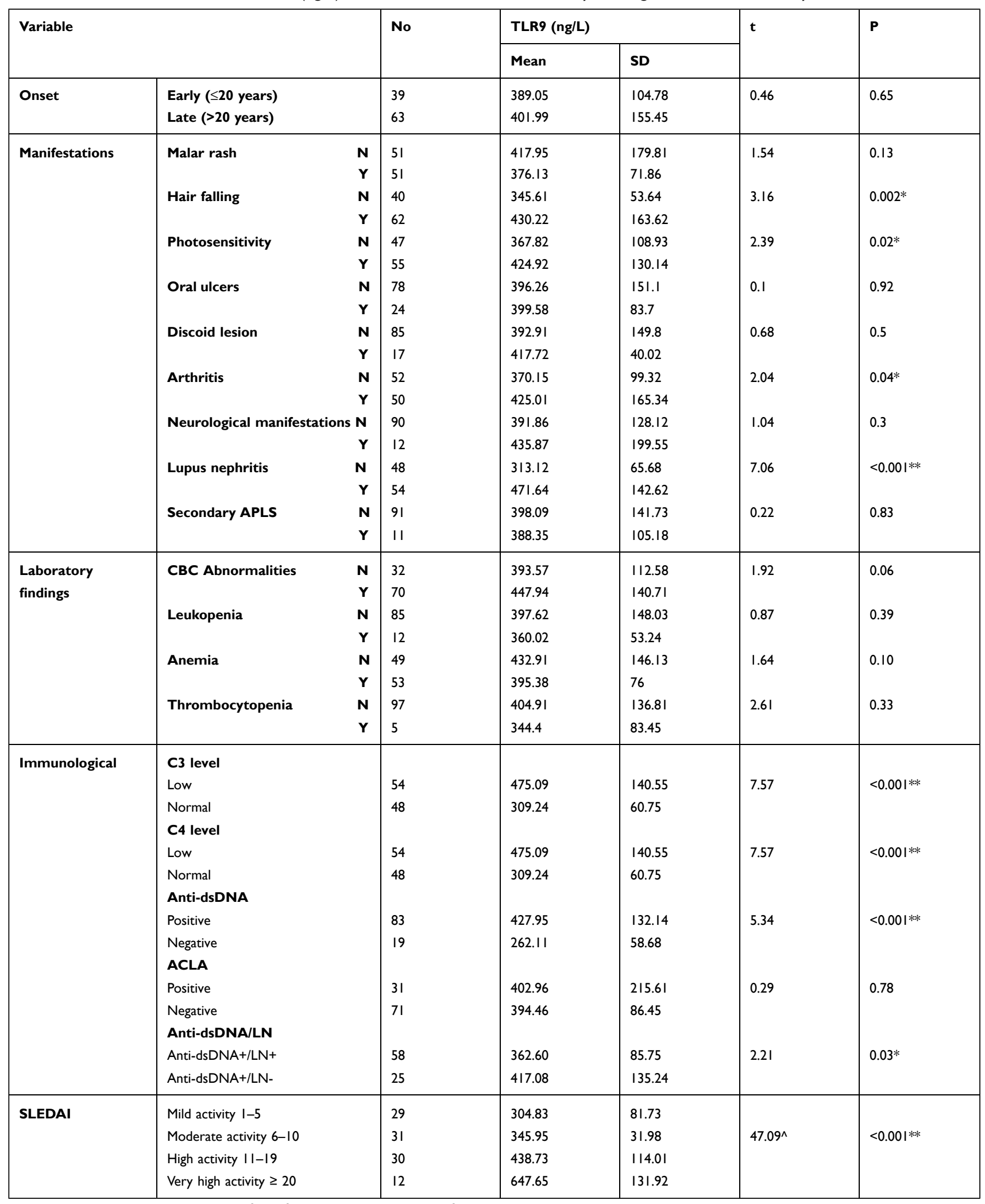

Notes: Normal WBCs count $=4-11 \times 10^{3} / \mathrm{mm}^{3}$ and leukopenia $<4000 / \mathrm{mm}^{3}$, Normal hemoglobin level $=12-16 \mathrm{~g} / \mathrm{dl}$ and anemia $<12 \mathrm{~g} / \mathrm{dl}, \mathrm{Normal}$ platelet count $=150-400$ $\times 10^{3} / \mathrm{mm}^{3}$ and thrombocytopenia $<100,000 / \mathrm{mm}^{3}$, Normal C3 level =90- $210 \mathrm{mg} / \mathrm{dl}$, Normal C4 level =13- $75 \mathrm{mg} / \mathrm{dl}$. ^ANOVA test; *Significant; **Highly significant. Abbreviations: SD, standard deviation; Del, deletion; Ins, insertion; APLS, antiphospholipid syndrome; CBC, complete blood count; C3, complement 3 level; C4, complement 4 level; ANA, antinuclear antibodies; Anti-ds DNA, Anti-double stranded DNA antibodies; ACLA, anticardiolipin antibodies; SLEDAI, systemic lupus erythematosus disease activity index; $t$, independent $t$-test; 


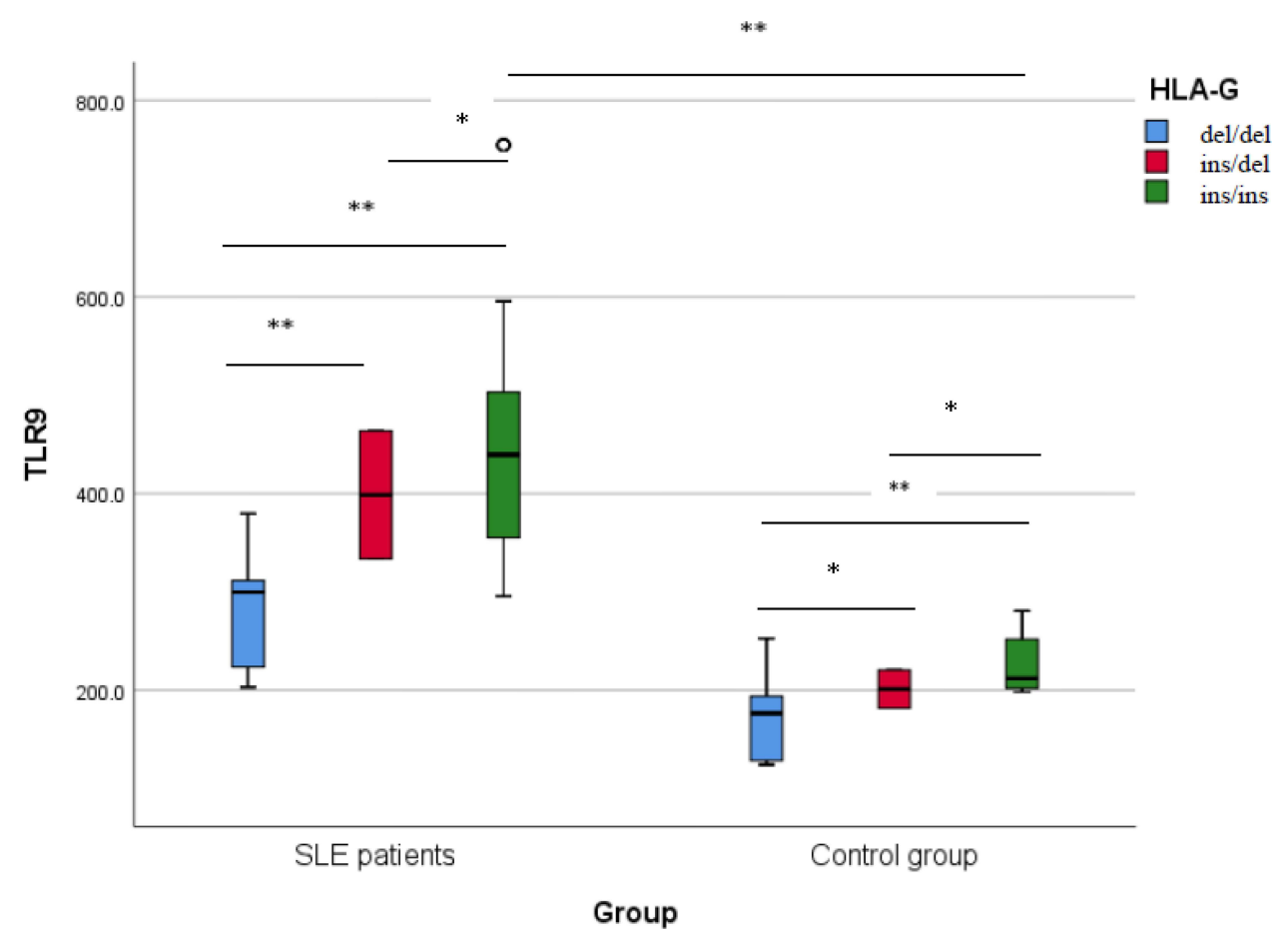

Figure 3 TLR9 level (ng/L) among different HLA-G genotypes in the studied participants. Comparing TLR9 levels among different HLA-G genotypes using Tukey post hoc test demonstrates a significant increase $(P<0.001)$ in individuals with ins/ins genotype compared to other genotypes whether in SLE patients $(n=102)$ or control group $(n=$ 102). *Significant, **Highly significant.

The different results obtained among different studies may be attributed to other environmental or epigenetic factors that influence disease development. ${ }^{41}$ However, the influence of other genetic polymorphisms, which are not included in the present study, could not be excluded. $H L A-G$ encodes two potentially functional polymorphisms in the 3' UTR, a-14bp insertion/deletion (14bp ins/del, rs371194629) and a single nucleotide polymorphism $+3142 \mathrm{G} / \mathrm{C}$ rs1063320, previously reported to affect $H L A-G$ expression level and to be associated with susceptibility to SLE. It is interesting to point out that the two polymorphisms are in high linkage disequilibrium (LD) ${ }^{42}$ In addition, the $H L A-G$ gene is strongly linked to other SLE-associated HLA variants differently present in these ethnically diverse populations, in particular HLA-DRB1 alleles. ${ }^{16}$ The DRB1*03:01 haplotype for example has been shown to be in strong LD with the 14 bp ins allele and was found to be a major risk allele for SLE among Egyptians. ${ }^{43}$ However, among the Japanese population, it has a very rare frequency $(0.1 \%) .{ }^{16}$ This probably reflects the complex genetic platform that is needed to work together or interact in a certain way in different populations driving SLE development.

The results of this study showed no significant association between $H L A-G 14 \mathrm{bp}$ ins/del genotypes and disease onset or disease duration among SLE Egyptian patients. In contrast, in Japanese population, Hachiya and coauthors recorded a significant association $(\mathrm{P}=0.0067)$ of the $14 \mathrm{bp}$ ins/ins genotype and early-onset $($ age $<20)$ SLE. ${ }^{16}$

The current study found that LN and hair falling were significantly higher in patients with the homozygote ins/ins genotype ( $\mathrm{P}=0.02,0.002$, respectively). In contrast, arthritis was significantly higher in patients with the homozygote del/del genotype. The expression of non-classical immunoregulatory MHC class I molecules as HLA-G has been suggested previously to protect hair follicles, as immune-privileged sites, from undesired immune responses by creating an immunoinhibitory signaling milieu suppressing both natural killer and cytotoxic T cells. ${ }^{44}$ Similarly, in renal tissue of SLE patients, HLA-G expression has been shown to attenuate LN through inhibiting dendritic cell maturation and causing B1 cell depletion. ${ }^{45}$ Therefore, it is possible that decreased expression of HLA-G which may associate with genetic polymorphisms could account for the excessive activation of multiple immune cells observed in SLE patients resulting in inflammation and tissue destruction. Contradicting results have been reported concerning the association of the $14 \mathrm{bp}$ ins/del genotypes with different SLE phenotypes. In pediatric Brazilian patients, Cavalcanti and coauthors 
found that patients with the $14 \mathrm{bp}$ deletion allele and $14 \mathrm{bp}$ del/del genotype exhibited a significantly increased risk of developing $\mathrm{LN}(\mathrm{OR}=2.76,95 \%$ confidence interval $[\mathrm{CI}]=1.17-6.52, \mathrm{P}=0.028$ and $\mathrm{OR}=8.00,95 \% \mathrm{CI}=1.57-40.65$, $\mathrm{P}=0.006$, respectively ${ }^{46}$ which comes consistent with the current study. Hachiya and coauthors, on the other hand, reported no association between $H L A-G 14 \mathrm{bp}$ ins/del and nephritis among Japanese SLE patients. ${ }^{16}$ An increased frequency of heterozygotes (ins/del) in photosensitive patients and homozygotes for deletion (del/del) in patients with arthritis has been reported among SLE patients in Brazil. ${ }^{47}$ Interestingly, in another Brazilian study, no significant association between $H L A-G$ ins/del and clinical manifestations of SLE was found. ${ }^{48}$ The effects of the $H L A-G$ ins/del (rs371194629) polymorphism on clinical manifestations in various ethnicities remain poorly understood. However, these differences may be attributed to the different sizes or ages of the studied groups, their genetic heterogeneity, their different interaction with environmental factors, or different pathogenesis.

In the current study, a significant association between the ins/ins genotype and disease activity (denoted by SLEDAI) was found. In agreement with this finding, Veit and coauthors reported a significant difference $(\mathrm{P}=0.035)$ in SLEDAI scores among different $H L A-G$ genotypes with the heterozygote group (ins/del) recording the lowest mean rank. ${ }^{47}$ However, Consiglio and coauthors declared no significant association between SLEDAI and homozygosis to a particular allele among genotypes of the $3^{\prime}$ UTR polymorphism ( $H L A-G 14 \mathrm{bp}$ ins/del) ${ }^{48}$ It is possible that the different genetic makeup of different patients or other environmental factors contributed to these conflicting results.

Concerning TLR9 serum level, the current study recorded a significantly higher level among SLE patients compared to the control group $(\mathrm{P}<0.001)$. This finding is consistent with the results of previous studies. ${ }^{49,50}$ This could be attributed to the excessive availability of immunogenic cell-free DNA, in SLE patients, that results from defects in its digestion or clearance or its structural modification that can stimulate and even induce TLR9 expression. ${ }^{24,51}$ Furthermore, this study recorded a significantly higher TLR9 level $(\mathrm{P}<0.05)$ among patients with hair falling, photosensitivity, arthritis, and LN. The association between TLR9 and different clinical parameters remains controversial. In a previous study, Shahin and coauthors reported a significant association between TLR9 and photosensitivity, myositis, psychosis, and pleurisy among Egyptian SLE patients. ${ }^{52}$

In this study, SLE patients with higher SLEDAI indexes, low C3 and C4 levels and positive anti-ds DNA autoantibodies (indicating disease activity) ${ }^{53}$ showed a significantly higher expression of TLR9 than those in the remission stage or healthy controls. This finding is well matched with previous studies which have demonstrated that TLR9 is highly expressed in SLE patients and that TLR9 expression in patients with active SLE is increased compared to healthy controls. ${ }^{23,24,54}$ Additionally, the positive correlation between the expression of TLR9 and both SLEDAI and anti-ds DNA in SLE patients has been previously reported. ${ }^{24,50,55}$ Yuan and coauthors further demonstrated that increased expression of TLR9 could indicate a poor prognosis in SLE patients suggesting it as a putative marker to predict the outcome of SLE patients. ${ }^{23}$ However, in another study, no correlation between TLR9 expression, when measured in peripheral blood mononuclear cells, and SLEDAI was found. ${ }^{56}$

As anti-ds DNA autoantibodies have been linked to $\mathrm{LN},{ }^{57}$ a major end organ disease in SLE, patients with positive anti-ds DNA were further divided in this study into two groups based on the presence (anti-dsDNA+/LN+) and absence of LN (anti-dsDNA+/LN-). A significant increase in TLR9 expression in the anti-dsDNA+/LN+ group as opposed to the anti-dsDNA+/LN- group was found $(\mathrm{P}=0.03)$. This comes consistent with what has been reported previously. ${ }^{58}$ It has been suggested that the accumulation of extracellular dsDNA fragments and DNA-containing immune complexes in SLE patients could induce high TLR9 expression. ${ }^{23}$ However, the findings of this study may indicate that the presence of antidsDNA may not be the sole factor correlating with TLR9 upregulation and that the presence of LN appears to augment TLR9 expression further. Additionally, this may reflect the extensive damage in renal tissues induced by anti-dsDNA that not only results in the accumulation of extracellular dsDNA but otherwise the exposure of a multitude of dsDNA fragments that remain sequestered in the cells.

The results of this study demonstrated a significant association $(\mathrm{P}<0.001)$ between $H L A-G 14 \mathrm{bp}$ ins/del genotypes and TLR9 level, as those with genotype ins/ins had the highest TLR9 level in both cases and controls. Up to our knowledge, this association has not been addressed before. However, it could be attributed to the indirect effect of the decreased expression level of HLA-G molecules associated with the ins/ins genotype ${ }^{18}$ which limits its immunomodulatory effect and enhances, on the other side, the immunopathologic mechanisms in SLE patients. This could eventually 
aggravate tissue damage and release excess extracellular nucleic acids enhancing the induction of TLR9 expression. It is noteworthy that type 1 IFN (induced by TLR9 signaling) is a main inducer of HLA-G molecules, ${ }^{59}$ which constitutes an immune checkpoint mechanism exerting a suppressive function and impairing the effector functions of both innate and adaptive immune-competent cells.

Nevertheless, the limited sample size included without considering the heterogeneity of both demographic and clinical aspects, the lack of measuring serum HLA-G level and the lack of detection of other forms of polymorphisms affecting HLA-G expression may constitute some limitations of the current study.

\section{Conclusion}

$H L A-G 14$ bp ins/del polymorphism in the 3'UTR constitutes a significant risk factor for SLE susceptibility in Egyptian patients in whom a significantly higher level of TLR9 was detected that may support a role for HLA-G and TLR9 in the pathophysiology of SLE in Egyptian patients.

\section{Disclosure}

The authors report no conflicts of interest in this work.

\section{References}

1. Chen L, Wang YF, Liu L, et al. Genome-wide assessment of genetic risk for systemic lupus erythematosus and disease severity. Hum Mol Genet. 2020;29(10):1745-1756. doi:10.1093/hmg/ddaa030

2. Barbhaiya M, Costenbader KH. Environmental exposures and the development of systemic lupus erythematosus. Curr Opin Rheumatol. 2016;28 (5):497-505. doi:10.1097/BOR.0000000000000318

3. Wang YF, Zhang Y, Lin Z, et al. Identification of 38 novel loci for systemic lupus erythematosus and genetic heterogeneity between ancestral groups. Nat Commun. 2021;12(1):772. doi:10.1038/s41467-021-21049-y

4. Attia DH, Dorgham DA, El Maghraby AA, et al. Autoimmune regulator gene polymorphisms in Egyptian systemic lupus erythematosus patients: preliminary results. Int $J$ Rheumatol. 2021;2021(28):5546639. doi:10.1155/2021/5546639

5. Zedan MM, Attia ZR, Abd El Azeem RA, Mutawi TM, El Shehawy AS, Bakr A. Genetic polymorphisms in genes involved in the type I interferon system (IFIH1/MDA-5, TNFAIP3/A20, and STAT4): association with SLE risk in Egyptian children and adolescents. J Inflamm Res. 2021;15:3349-3358. doi:10.2147/JIR.S309008

6. Ali YBM, El-Akhras BA, El-Shazly R, Bassyouni IH. Genetic polymorphisms of IL-27 and risk of systemic lupus erythematosus disease in the Egyptian population. Clin Rheumatol. 2021;40(12):4899-4907. doi:10.1007/s10067-021-05858-6

7. Abo El-Khair SM, Sameer W, Awadallah N, Shaalan D. Programmed cell death 1 gene polymorphism as a possible risk for systemic lupus erythematosus in Egyptian females. Lupus. 2019;28(12):1427-1434. doi:10.1177/0961203319878493

8. Al-Kholy W, Elsaid A, Sleem A, Fathy H, Elshazli R, Settin A. TNF- $\alpha-308$ G > A and IFN- $\gamma+874$ A $>$ T gene polymorphisms in Egyptian patients with lupus erythematosus. Meta Gene. 2016;4(9):137-141. doi:10.1016/j.mgene.2016.06.002

9. Castelli EC, Ramalho J, Porto IO, et al. Insights into HLA-G genetics provided by worldwide haplotype diversity. Front Immunol. 2014;5:476. doi:10.3389/fimmu.2014.00476

10. Xu X, Zhou Y, Wei H. Roles of HLA-G in the maternal-fetal immune microenvironment. Front Immunol. 2020;22(11):592010. doi:10.3389/ fimmu.2020.592010

11. Carosella ED, Rouas-Freiss N, Tronik-le Roux D, Moreau P, LeMaoult J. HLA-G: an immune checkpoint molecule. Adv Immunol. 2015;127:33-144. doi:10.1016/bs.ai.2015.04.001

12. Carosella ED, Favier B, Rouas-Freiss N, Moreau P, Lemaoult J. Beyond the increasing complexity of the immunomodulatory HLA-G molecule. Blood. 2008;111(10):4862-4870. doi:10.1182/blood-2007-12-127662

13. Rizzo R, Bortolotti D, Bolzani S, et al. HLA-G molecules in autoimmune diseases and infections. Front Immunol. 2014;5:592. doi:10.3389/ fimmu.2014.00592

14. Rizzo R, Hviid TV, Govoni M, et al. HLA-G genotype and HLA-G expression in systemic lupus erythematosus: HLA-G as a putative susceptibility gene in systemic lupus erythematosus. Tissue Antigens. 2008;71(6):520-529. doi:10.1111/j.1399-0039.2008.01037.x

15. Catamo E, Addobbati C, Segat L, et al. Comprehensive analysis of polymorphisms in the HLA-G $5^{\prime}$ upstream regulatory and $3^{\prime}$ untranslated regions in Brazilian patients with systemic lupus erythematosus. Tissue Antigens. 2015;85(6):458-465. doi:10.1111/tan.12545

16. Hachiya Y, Kawasaki A, Oka S, et al. Association of HLA-G 3' untranslated region polymorphisms with systemic lupus erythematosus in a Japanese population: a case-control association study. PLoS One. 2016;11(6):e0158065. doi:10.1371/journal.pone.0158065

17. Rousseau P, Le Discorde M, Mouillot G, Marcou C, Carosella ED, Moreau P. The 14 bp deletion-insertion polymorphism in the 3' UT region of the HLA-G gene influences HLA-G mRNA stability. Hum Immunol. 2003;64(11):1005-1010. doi:10.1016/j.humimm.2003.08.347

18. Chen XY, Yan WH, Lin A, Xu HH, Zhang JG, Wang XX. The 14 bp deletion polymorphisms in HLA-G gene play an important role in the expression of soluble HLA-G in plasma. Tissue Antigens. 2008;72(4):335-341. doi:10.1111/j.1399-0039.2008.01107.x

19. Donadi EA, Castelli EC, Arnaiz-Villena A, Roger M, Rey D, Moreau P. Implications of the polymorphism of $H L A$ - $G$ on its function, regulation, evolution, and disease association. Cell Mol Life Sci. 2011;68(3):369-395. doi:10.1007/s00018-010-0580-7

20. Alvarez M, Piedade J, Balseiro S, Ribas G, Regateiro F. HLA-G 3'-UTR SNP and 14-bp deletion polymorphisms in Portuguese and Guinea-Bissau populations. Int J Immunogenet. 2009;36(6):361-366. doi:10.1111/j.1744-313X.2009.00875.x 
21. Amodio G, Gregori S. HLA-G genotype/expression/disease association studies: success, hurdles, and perspectives. Front Immunol. 2020;11:1178. doi:10.3389/fimmu.2020.01178

22. Własiuk P, Tomczak W, Zając M, Dmoszyńska A, Giannopoulos K. Total expression of HLA-G and TLR-9 in chronic lymphocytic leukemia patients. Hum Immunol. 2013;74(12):1592-1597. doi:10.1016/j.humimm.2013.08.277

23. Yuan Y, Zhao L, Ye Z, Ma H, Wang X, Jiang Z. Association of Toll-like receptor 9 expression with prognosis of systemic lupus erythematosus. Exp Ther Med. 2019;17(4):3247-3254. doi:10.3892/etm.2019.7290

24. Rao H, Zeng Q, Liang Y, Xiao C, Xie S, Xu X. Correlation between TLR9 expression and cytokine secretion in the clinical diagnosis of systemic lupus erythematosus. Mediators Inflamm. 2015;2015:710720. doi:10.1155/2015/710720

25. Tilstra JS, John S, Gordon RA, et al. B cell-intrinsic TLR9 expression is protective in murine lupus. J Clin Invest. $2020 ; 130(6): 3172-3187$. doi:10.1172/JCI132328

26. Fillatreau S, Manfroi B, Dörner T. Toll-like receptor signalling in B cells during systemic lupus erythematosus. Nat Rev Rheumatol. 2021;17 (2):98-108. doi:10.1038/s41584-020-00544-4

27. Suurmond J, Diamond B. Autoantibodies in systemic autoimmune diseases: specificity and pathogenicity. J Clin Invest. $2015 ; 125(6): 2194-2202$. doi: $10.1172 / \mathrm{JCI} 78084$

28. Jackson SW, Scharping NE, Kolhatkar NS, et al. Opposing impact of B cell-intrinsic TLR7 and TLR9 signals on autoantibody repertoire and systemic inflammation. J Immunol. 2014;192(10):4525-4532. doi:10.4049/jimmunol.1400098

29. Petri M, Orbai AM, Alarcón GS, et al. Derivation and validation of the systemic lupus international collaborating clinics classification criteria for systemic lupus erythematosus. Arthritis Rheum. 2012;64(8):2677-2686. doi:10.1002/art.34473

30. Gladman DD, Ibañez D, Urowitz MB. Systemic lupus erythematosus disease activity index 2000. J Rheumatol. 2002;29(2):288-291.

31. Yan WH, Lin A, Li M, Xu HH, Zhang ZP, Wang XX. Analysis of the 14 bp insertion and deletion polymorphism in human leukocyte antigen-G gene in two Chinese ethnic populations. Tissue Antigens. 2008;71(3):227-233. doi:10.1111/j.1399-0039.2008.01006.x

32. Sestak AL, Fürnrohr BG, Harley JB, Merrill JT, Namjou B. The genetics of systemic lupus erythematosus and implications for targeted therapy. Ann Rheum Dis. 2011;70(Suppl 1):i37-43. doi:10.1136/ard.2010.138057

33. El Shahaway AA, Salah W, Shazly SA, Abd Elhady RR. Role of HLA-G 14 bp polymorphism and soluble HLA-G level in recurrent spontaneous abortion. Egypt J Med Microbiol. 2019;28:4.

34. Farghaly WM, Saad Eldien HM, Sayed MA, et al. The relationship of HLA-G 14-bp insertion/deletion genetic polymorphism to the risk of multiple sclerosis and its clinical phenotypes. Egypt J Neurol Psychiatry Neurosurg. 2021;57(1):58. doi:10.1186/s41983-021-00312-5

35. Tawfeek GA, Alhassanin S. HLA-G gene polymorphism in Egyptian patients with non-Hodgkin lymphoma and its clinical outcome. Immunol Invest. 2018;47(3):315-325. doi:10.1080/08820139.2018.1430826

36. Bae SC, Lee YH. Association of HLA-G polymorphisms with systemic lupus erythematosus and correlation between soluble HLA-G levels and the disease: a meta-analysis. Z Rheumatol. 2021;80(1):96-102. doi:10.1007/s00393-020-00783-6

37. Lee YH, Bae SC. Association between a functional HLA-G 14-bp insertion/deletion polymorphism and susceptibility to autoimmune diseases: a meta-analysis. Cell Mol Biol. 2015;61(8):24-30.

38. Zhang X, Li S, Zhang Y, et al. Meta-analysis of the relationship between $14 \mathrm{bp}$ insertion/deletion polymorphism of HLA-G gene and susceptibility to systemic lupus erythematosus. Hum Immunol. 2014;75(12):1171-1176. doi:10.1016/j.humimm.2014.10.008

39. Wu FX, Wu LJ, Luo XY, et al. Lack of association between HLA-G 14-bp polymorphism and systemic lupus erythematosus in a Han Chinese population. Lupus. 2009;18(14):1259-1266. doi:10.1177/0961203309345756

40. Al-hasso IKQ, Al-Derzi AR, Abbas AA, Isho F, Alnuimi AS. The impact of the HLA-G 14 BP insertion/deletion polymorphism and soluble HLA-G serum level in systemic lupus erythematosus. Ann Trop Med Public Health. 2020;23(S12):SP231227. doi:10.36295/ASRO.2020.231227

41. Farivar S, Shaabanpour Aghamaleki F. Effects of major epigenetic factors on systemic lupus erythematosus. Iran Biomed J. 2018;22(5):294-302. doi:10.29252/ibj.22.5.294

42. Castelli E, Mendes-Junior C, Deghaide N, et al. The genetic structure of 3'untranslated region of the HLA-G gene: polymorphisms and haplotypes. Genes Immun. 2010;11(2):134-141. doi:10.1038/gene.2009.74

43. El-Haj IM, Ismail AM, El-Halafawy KE, Mortada WI, El-Sherbiny SM. Molecular analysis of HLA-DRB1 allelic associations with systemic lupus erythematous and lupus nephritis in Egyptians. Int $J$ Adv Res. 2014;2(7):831-838.

44. Bertolini M, McElwee K, Gilhar A, Bulfone-Paus S, Paus R. Hair follicle immune privilege and its collapse in alopecia areata. Exp Dermatol. 2020;29(8):703-725. doi:10.1111/exd.14155

45. Foschi V, Bortolotti D, Doyle AF, et al. Analysis of HLA-G expression in renal tissue in lupus nephritis: a pilot study. Lupus. 2019;28 (9):1091-1100. doi:10.1177/0961203319860582

46. Cavalcanti A, Almeida R, Mesquita Z, Duarte ALBP, Donadi EA, Lucena-Silva N. Gene polymorphism and HLA-G expression in patients with childhood-onset systemic lupus erythematosus: a pilot study. HLA. 2017;90(4):219-227. doi:10.1111/tan.13084

47. Veit TD, Cordero EA, Mucenic T, et al. Association of the HLA-G 14 bp polymorphism with systemic lupus erythematosus. Lupus. 2009;18 (5):424-430. doi:10.1177/0961203308098187

48. Consiglio CR, Veit TD, Monticielo OA, et al. Association of the HLA-G gene $+3142 \mathrm{C}>\mathrm{G}$ polymorphism with systemic lupus erythematosus. Tissue Antigens. 2011;77(6):540-545. doi:10.1111/j.1399-0039.2011.01635.x

49. Mu R, Sun XY, Lim LT, et al. Toll-like receptor 9 is correlated to disease activity in Chinese systemic lupus erythematosus population. Chin Med J. 2012;125(16):2873-2877.

50. Li XL, Zhang Z, Zhang H. Expression level of TLR9, but not hypomethylation, is correlated with SLE disease activity. Physiol Res. 2019;68 (6):973-980. doi:10.33549/physiolres.934167

51. Soni C, Reizis B. Self-DNA at the epicenter of SLE: immunogenic forms, regulation, and effects. Front Immunol. 2019;10:1601. doi:10.3389/ fimmu.2019.01601

52. Shahin RMH, El Khateeb E, Khalifa RH, El Refai RM. Contribution of Toll-Like receptor 9 gene single-nucleotide polymorphism to systemic lupus erythematosus in Egyptian patients. Immunol Invest. 2016;45(3):235-242. doi:10.3109/08820139.2015.1137934

53. Dema B, Charles N. Autoantibodies in SLE: specificities, isotypes and receptors. Antibodies. 2016;5(1):2. doi:10.3390/antib5010002

54. Mortezagholi S, Babaloo Z, Rahimzadeh P, et al. Evaluation of TLR9 expression on PBMCs and CpG ODN-TLR9 ligation on IFN- $\alpha$ production in SLE patients. Immunopharmacol Immunotoxicol. 2017;39(1):11-18. doi:10.1080/08923973.2016.1263859 
55. Ghaly NR, Kotb NA, Nagy HM, Rageh EM. Toll-like receptor 9 in systemic lupus erythematosus, impact on glucocorticoid treatment. J Dermatol Treat. 2013;24(6):411-417. doi:10.3109/09546634.2012.697110

56. Klonowska-Szymczyk A, Wolska A, Robak T, Cebula-Obrzut B, Smolewski P, Robak E. Expression of Toll-Like receptors 3, 7, and 9 in peripheral blood mononuclear cells from patients with systemic lupus erythematosus. Mediators Inflamm. 2014;2014:381418. doi:10.1155/2014/381418

57. Linnik MD, Hu JZ, Heilbrunn KR, Strand V, Hurley FL, Joh T. LJP 394 Investigator Consortium. Relationship between anti-double-stranded DNA antibodies and exacerbation of renal disease in patients with systemic lupus erythematosus. Arthritis Rheum. 2005;52(4):1129-1137. doi:10.1002/ art.20980

58. Chauhan SK, Singh VV, Rai R, Rai M, Rai G. Distinct autoantibody profiles in systemic lupus erythematosus patients are selectively associated with TLR7 and TLR9 upregulation. J Clin Immunol. 2013;33(5):954-964. doi:10.1007/s10875-013-9887-0

59. Alegre E, Rizzo R, Bortolotti D, Fernandez-Landázuri S, Fainardi E, González A. Some basic aspects of HLA-G biology. J Immunol Res. 2014;2014:657625.

\section{Publish your work in this journal}

The International Journal of General Medicine is an international, peer-reviewed open-access journal that focuses on general and internal medicine, pathogenesis, epidemiology, diagnosis, monitoring and treatment protocols. The journal is characterized by the rapid reporting of reviews, original research and clinical studies across all disease areas. The manuscript management system is completely online and includes a very quick and fair peer-review system, which is all easy to use. Visit http://www.dovepress.com/testimonials.php to read real quotes from published authors.

Submit your manuscript here: https://www.dovepress.com/international-journal-of-general-medicine-journal 